\title{
Classification and quantification of double superior vena cava evaluated by computed tomography imaging
}

\author{
Lin Zhang ${ }^{1 \#}$, Gonghao Ling ${ }^{2 \#}$, Yadong Gang ${ }^{2}$, Zhaoxia Yang ${ }^{2}$, Zhibing Lu' ${ }^{1}$ Xuedong Gan ${ }^{1}$, Hongqin \\ Liang $^{3}$, Yingting Zeng ${ }^{2}$, Xiaochun Zhang ${ }^{4}$ \\ ${ }^{1}$ Department of Cardiology, Zhongnan Hospital of Wuhan University, Wuhan, China; ${ }^{2}$ Department of Radiology, Zhongnan Hospital of Wuhan \\ University, Wuhan, China; ${ }^{3}$ Department of Radiology, Southwest Hospital, Third Military Medical University, Chongqing, China; ${ }^{4}$ Department of \\ Radiology, Guangzhou Women and Children's Medical Center, Guangzhou Medical University, Guangzhou, China \\ Contributions: (I) Conception and design: X Zhang, L Zhang, G Ling; (II) Administrative support: Z Lu, X Zhang; (III) Provision of study materials \\ or patients: X Zhang, G Ling, Y Gang; (IV) Collection and assembly of data: L Zhang, G Ling, Z Yang, H Liang, Y Zeng; (V) Data analysis and \\ interpretation: L Zhang, G Ling, X Zhang, Z Lu, X Gan; (VI) Manuscript writing: All authors; (VII) Final approval of manuscript: All authors.
}

\#These authors contributed equally to this work and should be considered as co-first authors.

Correspondence to: Xiaochun Zhang. Department of Radiology, Guangzhou Women and Children's Medical Center, Guangzhou Medical University, No. 9 Jinsui Road, Guangzhou 510623, China. Email: zxcylxyr@163.com.

Background: A double superior vena cava (DSVC) may cause technical difficulties in some cardiovascular procedures. However, no quantitative data exist to describe the morphological features of this anomaly.

Methods: From January 2015 to January 2019, the data of 128 consecutive patients diagnosed with DSVC on computed tomography (CT) images were retrospectively analyzed. We proposed an easy and rational method for DSVC classification based on the presence or absence of the left brachiocephalic vein (LBCV), the presence or absence of an anastomotic vein bridging the bilateral superior vena cava (SVC), and the drainage pattern of the left superior vena cava (LSVC). The following classifications were established: type I, LBVC absent, LSVC drainage into the right atrium via the coronary sinus; type II, LBCV present, LSVC drainage into the right atrium via the coronary sinus; type III, LBCV absent, LSVC drainage into the right atrium via the anastomosis; type IV, LBCV present, LSVC drainage into the right atrium via the anastomosis. The length, diameter, and area of the bilateral SVC and the coronary sinus were carefully measured across the 4 types.

Results: Type I was the most frequently occurring type (66 of 128, 51.6\%), followed by type II (43 of 128 , $33.6 \%$ ), then type III (15 of 128, 11.7\%), and type IV (4 of 128, 3.1\%). The LSVC was significantly longer than the right SVC (RSVC) in all 4 types, and the diameters of the LSVC were significantly larger in types without the LBCV (i.e., types I and III) $(\mathrm{P}<0.0001$ for all). Additionally, the diameter of the coronary sinus in types I and II was triple that in types III and IV $(\mathrm{P}<0.0001)$, which was thought to be due to increased venous blood reflux through the coronary sinus.

Conclusions: The anatomical features of DSVC can be satisfactorily depicted on CT. The quantitative measurement of this anomaly by the reporting radiologists could assist clinicians to minimize the procedureassociated risks.

Keywords: Double superior vena cava (DSVC); computed tomography (CT); classification; quantification

Submitted Dec 22, 2020. Accepted for publication Oct 19, 2021.

doi: $10.21037 /$ qims-20-1387

View this article at: https://dx.doi.org/10.21037/qims-20-1387 


\section{Introduction}

The superior vena cava (SVC) is the largest vein of the human body. If the common cardinal vein fails to regress in its early embryological development, it can form a left SVC (LSVC) known as a persistent LSVC, which together with the normal right SVC (RSVC), forms a double SVC (DSVC) (1-4). Persistent LSVC is the most common thoracic venous anomaly, affecting $0.5 \%$ to $2 \%$ of the general population and up to $10 \%$ of patients with congenital heart disease (CHD) (1). Persistent LSVC is benign in most cases; however, its presence is still of paramount clinical significance, as it may complicate cardiovascular catheterizations if the left subclavian approach is used to access the right heart $(2,4)$. It is also a relative contraindication to performing retrograde cardioplegia during cardiothoracic surgeries, as it can result in excessive runoff of solution into the persistent LSVC and the right atrium, causing insufficient myocardial perfusion (5). Additionally, an LSVC might be related to abnormalities in the cardiac conduction system (6-9). Despite its significance, previous studies on the LSVC largely comprise case reports, and no quantitative data have been made available, which restricts our understanding of this anomaly. Thus, we sought to examine a series of 128 patients diagnosed with DSVC to define the anatomical features of the anomaly and quantitatively measure its key structures to provide additional information about DSVC and advocate that more clinical attention be paid to this anomaly.

\section{Methods}

\section{Study population}

Between January 2015 and January 2019, the data of patients who underwent chest enhancement computed tomography (CT) scans at Zhongnan Hospital, Wuhan University were retrospectively analyzed to detect the presence of a DSVC. The demographic and clinical information of all the patients were obtained from their medical records. Of the 126,291 patients who underwent CT scans, 128 patients were diagnosed with DSVC $(0.1 \%$ of the study population). Of the 74 patients known to have CHD, 8 (10.8\%) had DSVC.

\section{CT image acquisition}

Patients were placed in the supine head-first position for all the CT scans. Either a GE 750 HD 64-slice single- source scanner (GE Healthcare, Waukesha, Wisconsin), a Philips Ingenuity CT (Philips Medical Systems, Best, Netherlands), or a Siemens SOMATOM Definition 64-slice dual-source CT scanner (Siemens Medical Solutions, Forchheim, Germany) was used. The CT images were acquired during a single breath-hold to minimize motion artifacts. The scans were performed from the level of the upper thoracic inlet to the inferior level of the costophrenic angle with the following scanning parameters: voltage $120-140 \mathrm{kV}$, and current 60-170 mA (effective). Reconstruction was conducted at a specific post-processing workstation at $1 \mathrm{~mm}$ slice thickness and $1 \mathrm{~mm}$ intervals. Contrast-enhanced CT or multiphase CT angiography (CTA) was used depending on the clinical indications. The contrast dose ranged from $60-100 \mathrm{~mL}$ of iohexol (Omnipaque 350, GE Healthcare, Boston, MA, USA) in a dilution of either 70:30 or 50:50, and at a flow rate of 2.0 to $5.0 \mathrm{~mL} / \mathrm{s}$, depending on the patient's body mass index (BMI), weight, and creatinine level. Electrocardiographic gating was not used.

\section{Image analysis and measurements}

The reconstructed CT images were transmitted to the workstation and picture archiving and communication systems (PACS, Carestream Health Inc., Rochester, NY, USA) for curved planar reformation (CPR) and multiplanar reformation (MPR) post-processing. The CT images were analyzed carefully by two experienced radiologists. In the 128 patients with DSVC, the anatomical course, LSVC drainage pattern, and associated structures were carefully examined, and patients were classified into different groups according to the anomaly morphology described below (see Figures 1,2).

The cases were classified into the following 4 types based on the presence or absence of left brachiocephalic vein (LBCV), the presence or absence of an anastomotic vein bridging the bilateral SVC, and the drainage pattern of the LSVC: (I) type I, DSVC without LBCV, LSVC drainage into the right atrium via the coronary sinus (see Figure 1); (II) type II, DSVC with LBCV, LSVC drainage into the right atrium via the coronary sinus (see Figure $2 A, 2 B$ ); (III) type III, DSVC without LBCV, LSVC drainage into the right atrium via an anastomotic vein bridging the LSVC and RSVC (see Figure 2C,2D); and (IV) type IV, DSVC with $\mathrm{LBCV}$, LSVC drainage into the right atrium via an anastomotic vein (see Figure $2 E, 2 F$ ).

The following quantitative measurements taken from 

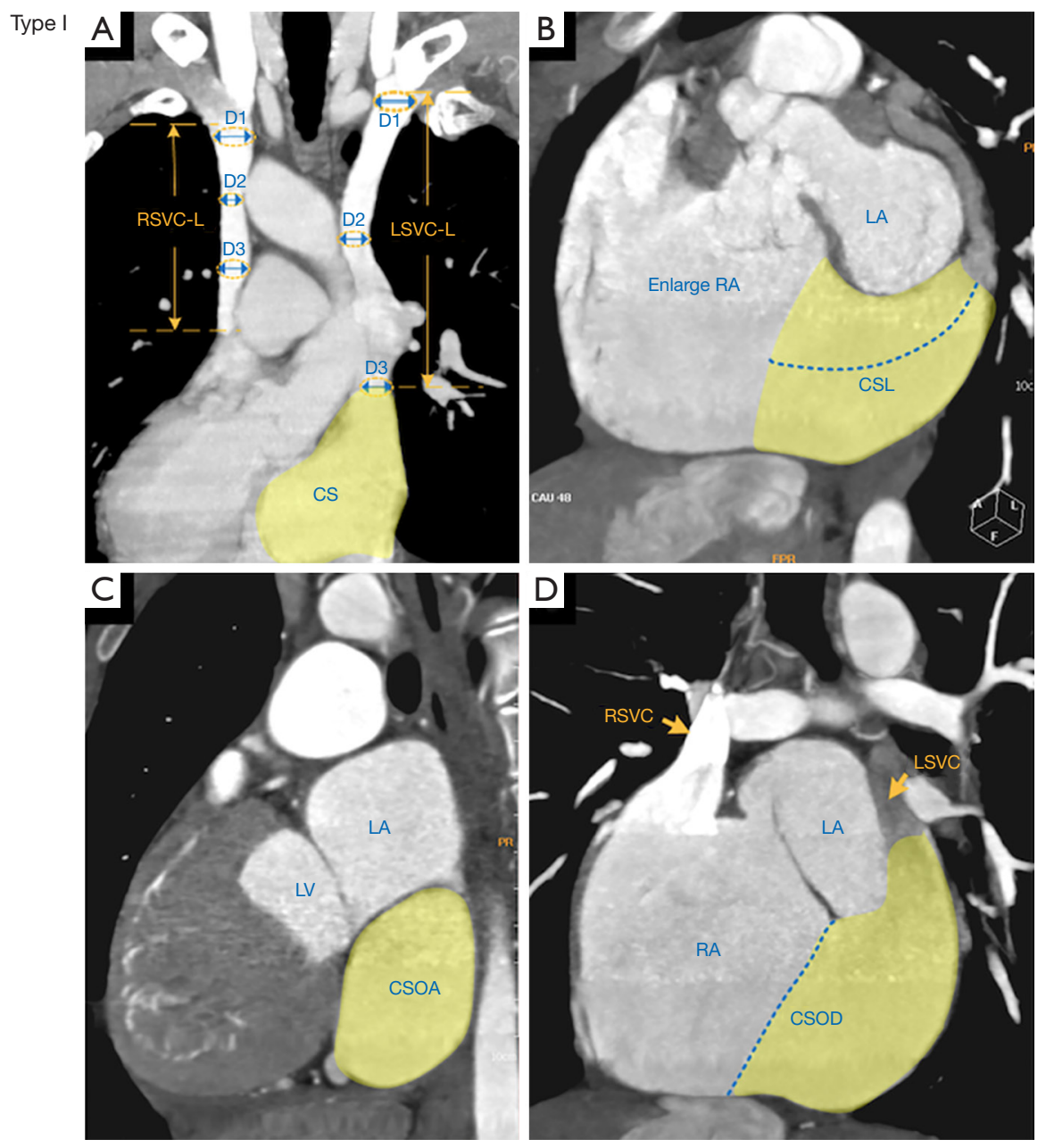

Figure 1 Representative illustration of the quantitative measurements of anatomical structures in type I DSVC. (A) Coronal twodimensional maximum intensity projection (MIP) image showing measurements of length (double yellow arrows) and diameter (double blue arrows); (B) oblique coronal image showing enlarged RA and CSL measurement (blue dotted curve); (C) transverse image of the coronary sinus ostium showing the measurements of the CSOA (yellow shading); (D) oblique sagittal image showing the measurements of the CSOD (blue dotted line). LA, left atrium; RA, right atrium; LV, left ventricle; CS, coronary sinus; CSL, length of coronary sinus; CSOA, area of coronary sinus ostium; CSOD, diameter of coronary sinus ostium; LSVC-L, length of left superior vena cava; RSVC-L, length of right superior vena cava.

the CT images (see Figure 1): the length of the RSVC (RSVC-L) was measured from the confluence of the left and right brachiocephalic veins (or from the level of the first sternocostal joint on the right if there was no LBCV) to the entrance of the right atrium; the length of the LSVC (LSVC-L) was measured from the level of the LBCV opening (or the level of the first sternocostal joint on the left if there was no LBCV), to either the coronary sinus entrance to the LSVC or the opening of the bilateral SVC anastomosis; the diameter of the bilateral SVC was obtained by calculating the average of the diameter of the proximal, middle and distal segments of the bilateral SVC at the best display slice; the area of the bilateral SVC was measured at the third segment, from the RSVC to the right atrial entrance; the length of the coronary sinus (CSL) was measured on the oblique coronal plane of the coronary sinus; the diameter of the coronary sinus ostium (CSOD) was measured at the coronary sinus entrance on the oblique sagittal view; and the area of coronary sinus ostium (CSOA) was measured on the transverse orientation of the coronary 


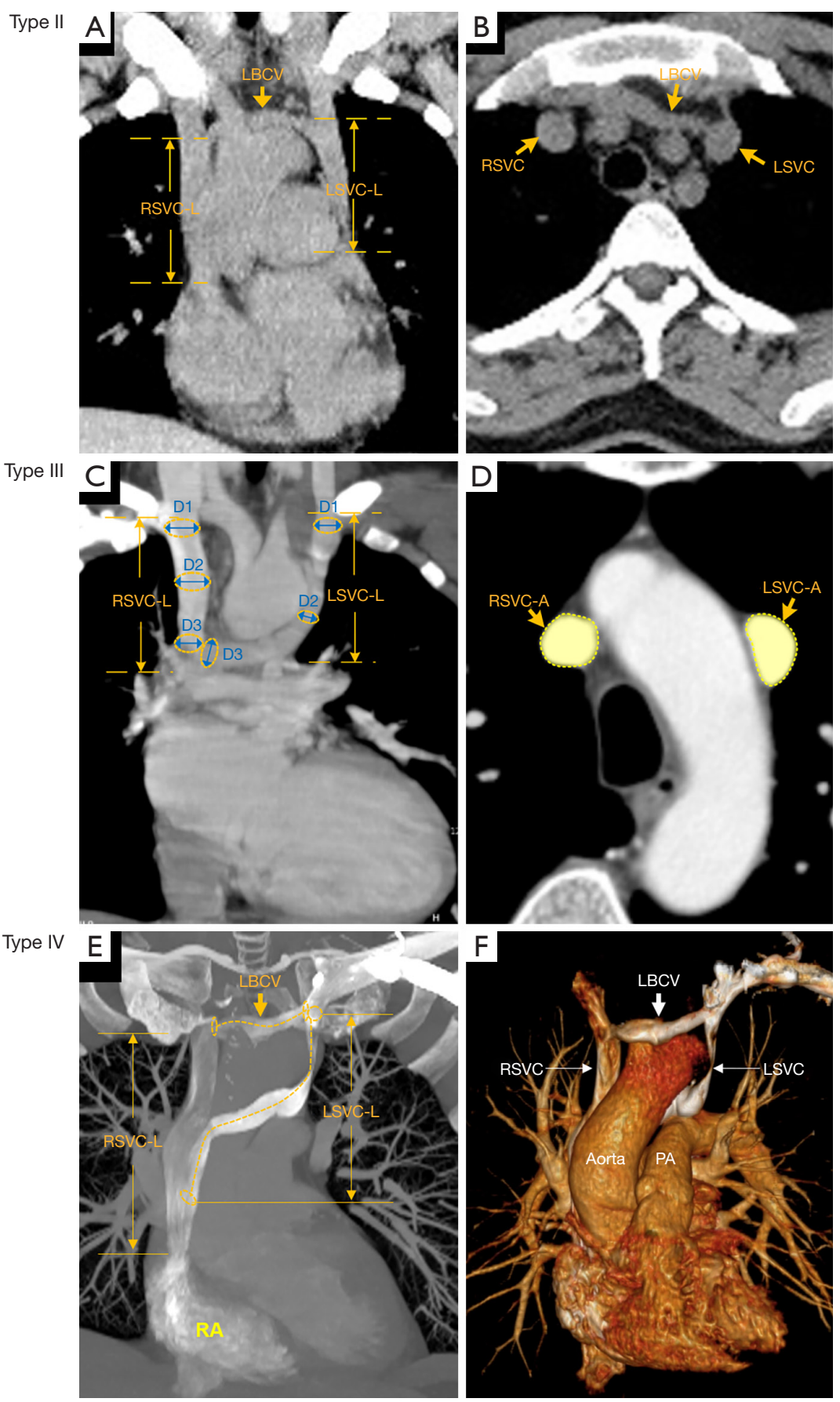

Figure 2 Representative patient images for type II, type III, and type IV DSVC. Type II: (A) coronal image showing the LBCV (yellow arrow) and measurements of the RSVC-L and LSVC-L (double yellow arrows); (B) axial image showing the LBCV, RSVC and LSVC (yellow arrows). Type III: (C) oblique coronal image showing measurements of the RSVC-L, LSVC-L (double yellow arrows) and diameter double (blue arrows) in a patient with type III DSVC; (D) axial image showing measurements of the RSVC-A and LSVC-A (yellow shading). Type IV: (E) coronal image showing the LBCV (yellow arrow), and measurements of the RSVC-L and LSVC-L (double yellow arrows); (F) volume rendering image showing the LSVC running between the aorta and the pulmonary artery (PA) window. LBCV, left brachiocephalic vein; LSVC-A, area of left superior vena cava; LSVC-L, length of left superior vena cava; RSVC-A, area of right superior vena cava; RSVC-L, length of right superior vena cava. 
Table 1 Baseline characteristics of 128 DSVC patients

\begin{tabular}{|c|c|c|c|c|c|}
\hline Characteristics & \multicolumn{4}{|c|}{ DSVC classification } & Total $(n=128)$ \\
\hline Age (years), mean $\pm S D$ & $47.3 \pm 14.3$ & $49.3 \pm 14.2$ & $45.1 \pm 17.2$ & $40.0 \pm 13.6$ & $47.5 \pm 14.6$ \\
\hline Women, n (\%) & $37(56.1)$ & $19(44.2)$ & $6(40.0)$ & $1(25.0)$ & $63(49.2)$ \\
\hline Men, n (\%) & $29(43.9)$ & $24(55.8)$ & $9(60.0)$ & $3(75.0)$ & $65(50.8)$ \\
\hline Sinus rhythm, n (\%) & $47(71.2)$ & $29(67.4)$ & $15(100.0)$ & $4(100.0)$ & $95(74.2)$ \\
\hline \multicolumn{6}{|l|}{ Reasons for CT scan } \\
\hline Lung diseases, n (\%) & $36(54.5)$ & $22(51.2)$ & $13(86.7)$ & $3(75.0)$ & $74(57.8)$ \\
\hline Congenital heart diseases, $\mathrm{n}(\%)$ & $3(4.5)$ & $2(4.7)$ & $2(13.3)$ & $1(25.0)$ & $8(6.3)$ \\
\hline
\end{tabular}

DSVC, double superior vena cava; SD, standard deviation.

sinus ostium.

\section{Statistics}

All data were analyzed using SPSS (version 18.0, IBM, Chicago, IL, USA). The continuous variables are expressed as mean \pm standard deviation (SD). Comparisons of the measurements between the LSVC and RSVC were performed using a paired $t$-test. Intergroup comparisons were performed using an independent samples $t$-test or a Mann-Whitney $U$ test as appropriate. A variance analysis and a post boc Bonferroni test were conducted for multiple comparisons. A two-tailed $\mathrm{P}<0.05$ was considered statistically significant.

\section{Ethical statement}

The study was conducted in accordance with the Declaration of Helsinki (as revised in 2013). The study was approved by the Ethics Committee of the Zhongnan Hospital, Wuhan University. In accordance with national legislation and the institutional requirements, written informed consent from the patients/participants was not required for this study.

\section{Results}

\section{Patient characteristics}

Patients' baseline characteristics are presented in Table 1 .
DSVC was detected in 128 patients $(0.1 \%$ of the study population). Of the 128 DSVC patients, 65 (50.8\%) were male, and 126 (98.4\%) were adults. The mean age of the participants was 47.2 years (range, $12-84$ years). Of the 128 DSVC patients, 8 (6.3\%) had concomitant congenital heart anomalies, including an atrial septal defect [2], aortic coarctation [2], unilateral absence of the left pulmonary artery [1], single atrium and ventricle [1], pulmonary stenosis [1], and complex congenital heart anomaly (atrial septal defect, ventricular septal defect, patent ductus arteriosus, aortic coarctation, overriding aorta) [1]. Further details about these 8 patients can be found in Table 2 .

\section{DSVC classification}

According to our newly proposed classification system, the distribution of the 128 DSVC patients was as follows: type I, 66 of 128 (51.6\%) (see Figure 1); type II, 43 of 128 (33.6\%) (see Figure 2A,2B); type III, 15 of 128 (11.7\%) (see Figure 2C,2D); and type IV, 4 of 128 (3.1\%) (see Figure 2E,2F). In the majority of patients (type I and type II; $85.2 \%$ ), the LSVC drained into the right atrium via the coronary sinus.

\section{Quantitative measurements of the bilateral SVC}

The length, diameter, and area of the RSVC and the LSVC were measured. The bilateral SVCs in each group were compared, and the results of the intergroup comparisons between the different types are summarized in Table 3. The LSVC-L was significantly longer than the RSVC-L 
Table 2 Eight congenital heart disease patients with concurrent DSVC

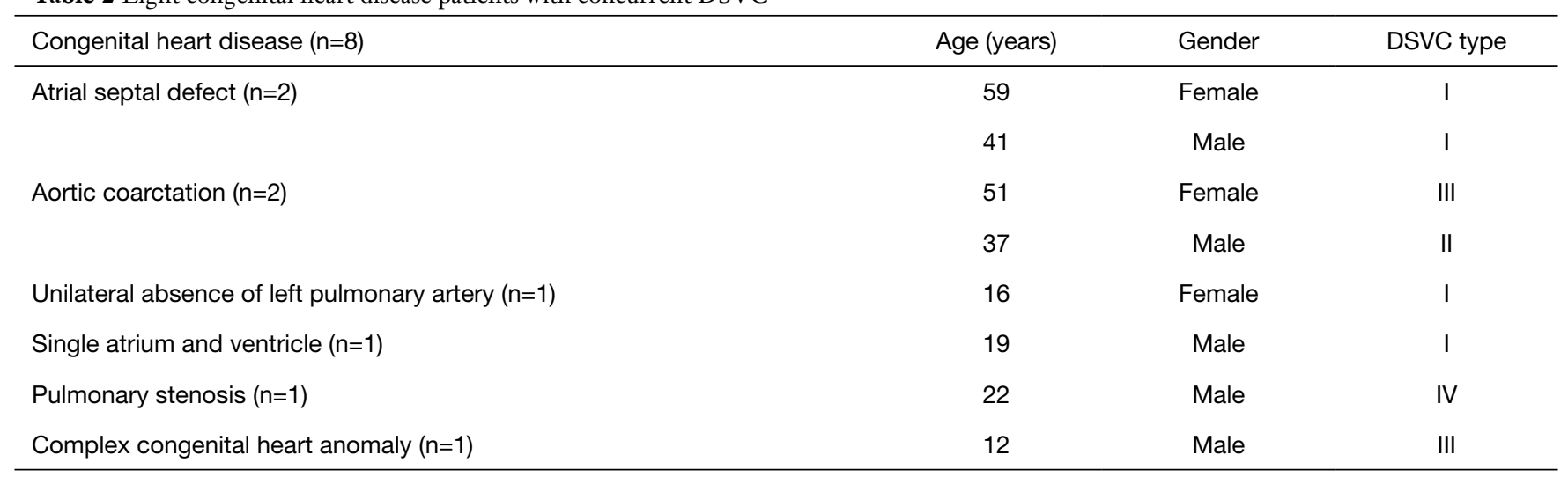

DSVC, double superior vena cava.

Table 3 Length, diameter, and area of the RSVC and LSVC in 128 DSVC patients

\begin{tabular}{|c|c|c|c|c|}
\hline Measurements & \multicolumn{4}{|c|}{ DSVC classification } \\
\hline \multicolumn{5}{|c|}{ Length $(\mathrm{mm})$, mean $\pm \mathrm{SD}$} \\
\hline RSVC & $42.7 \pm 10.8$ & $43.5 \pm 10.0$ & $43.5 \pm 10.4$ & $43.9 \pm 9.4$ \\
\hline LSVC & $130.3 \pm 12.3^{*}$ & $130.1 \pm 12.4$ & $100.8 \pm 10.1$ & $100.8 \pm 10.5$ \\
\hline \multicolumn{5}{|c|}{ Diameter $(\mathrm{mm})$, mean $\pm \mathrm{SD}$} \\
\hline RSVC & $13.9 \pm 3.5$ & $15.4 \pm 3.6$ & $13.9 \pm 3.5$ & $15.5 \pm 3.5$ \\
\hline LSVC & $16.1 \pm 3.4$ & $14.6 \pm 3.6$ & $16.1 \pm 3.5$ & $14.7 \pm 3.6$ \\
\hline$P$ value & $<0.0001$ & 0.361 & $<0.0001$ & 0.172 \\
\hline LSVC & $212.9 \pm 83.6$ & $177.8 \pm 83.0$ & $213.1 \pm 87.5$ & $177.5 \pm 82.1$ \\
\hline$P$ value & $<0.0001$ & 0.357 & $<0.0001$ & 0.172 \\
\hline
\end{tabular}

${ }^{*}, \mathrm{P}<0.0001$ of the SVC lengths between types I and II and types III and IV. DSVC, double superior vena cava; RSVC, right superior vena cava; LSVC, left superior vena cava.

$(\mathrm{P}<0.0001$ for each group). There was no significant difference in the RSVC-L among the 4 types (type I $v$ s. type II $v s$. type III $v s$. type IV: $42.7 \pm 10.8 v s$. $43.5 \pm 10.0$ vs. $43.5 \pm 10.4$ vs. $43.9 \pm 9.4 \mathrm{~mm}, \mathrm{P}=0.975)$. However, the LSVC-L varied in function of its drainage pattern. Specifically, the LSVC was significantly longer when it drained into the right atrium via the coronary sinus (types I and II) than when it drained from the RSVC into the right atrium via an anastomotic vein (types III and IV) $(\mathrm{P}<0.0001)$.

There was no significant difference among the 4 types in either the RSVC diameter or the LSVC diameter $(\mathrm{P}=0.163$, 0.148 , respectively). Additionally, the diameter was greater in the LSVC than in the RSVC in both type I and type III patients (type I, LSVC $16.1 \pm 3.4 \mathrm{~mm} v s$. RSVC $13.9 \pm 3.5 \mathrm{~mm}$, $\mathrm{P}<0.0001$; type III, LSVC $16.1 \pm 3.5 \mathrm{~mm}$ vs. RSVC $13.9 \pm 3.5 \mathrm{~mm}$, $\mathrm{P}<0.0001)$. Similar results were observed in the SVC area.

\section{Quantitative measurements of the coronary sinus}

The length, diameter, and area of each patient's coronary 
Table 4 Length, diameter and area of the coronary sinus in 128 DSVC patients

\begin{tabular}{lcccc}
\hline \multirow{2}{*}{ Measurements } & \multicolumn{4}{c}{ DSVC classification } \\
\cline { 2 - 5 } & Type I $(\mathrm{n}=66)$ & Type II $(\mathrm{n}=43)$ & Type III $(\mathrm{n}=15)$ & $34.3 \pm 9.3$ \\
\hline CSL $(\mathrm{mm})$ & $58.0 \pm 9.7^{\star}$ & $53.9 \pm 9.2$ & $11.2 \pm 1.8$ & $34.3 \pm 11.4$ \\
CSOD $(\mathrm{mm})$ & $30.0 \pm 3.8^{\$}$ & $28.0 \pm 3.7$ & $191.0 \pm 68.5$ & $11.4 \pm 2.1$ \\
CSOA $\left(\mathrm{mm}^{2}\right)$ & $865.2 \pm 160.9^{\#}$ & $748.6 \pm 133.8$ & $200.0 \pm 99.7$ \\
\hline
\end{tabular}

*, $\mathrm{P}<0.0001 ;{ }^{\$}, \mathrm{P}<0.0001 ;$ ", $\mathrm{P}<0.0001$ for comparisons between types I and II and types III and IV in terms of CSL, CSOD and CSOA, respectively. DSVC, double superior vena cava; CSL, length of coronary sinus; CSOD, diameter of coronary sinus ostium; CSOA, area of coronary sinus ostium.

sinus were obtained. The results of the comparisons between the groups are presented in Table 4. In contrast to types III and IV, the coronary sinus in types I and II was significantly lengthened and dilated ( $\mathrm{P}<0.0001$ in both groups) in which the LSVC drained through the coronary sinus into the right atrium. In relation to for the CSL, the measurements were $58.0 \pm 9.7 \mathrm{~mm}$ (type I), $53.9 \pm 9.2 \mathrm{~mm}$ (type II), $34.3 \pm 9.3 \mathrm{~mm}$ (type III), and $34.3 \pm 11.4 \mathrm{~mm}$ (type IV). No significant differences were found between type I and type II patient $(\mathrm{P}=0.138)$ or between type III and type IV patients $(\mathrm{P}=1.000)$. The diameter of the coronary sinus ostium in each type was as follows: $30.0 \pm 3.8 \mathrm{~mm}$ (type I), $28.0 \pm 3.7 \mathrm{~mm}$ (type II), $11.2 \pm 1.8 \mathrm{~mm}$ (type III), and $11.4 \pm 2.1 \mathrm{~mm}$ (type IV), and the first 2 types were significantly larger than the latter 2 types $(\mathrm{P}<0.0001)$. Similar results were found for the CSOA.

Subgroup analyses were then conducted according to patient gender, age, and BMI to examine if these factors affected the measurements. The overall results showed that the dimensions of the bilateral SVC and coronary sinus did not vary significantly within the subgroups of each DSVC type; however, there were some discrepancies among individuals. For further details, see Tables S1-S4.

\section{Discussion}

The present study quantitatively assessed the DSVC anomaly in a relatively large group of patients. A simple and rational approach to classifying DSVC was proposed based on the drainage pattern of the LSVC and the presence or absence of both the LBCV and an anastomotic vein. This approach may be useful for reporting radiologists and clinicians. The study showed that the most frequent type of DSVC (i.e., type I; 51.6\%) presented without the $\mathrm{LBCV}$ and with the LSVC draining into the right atrium via the coronary sinus. In most cases (type I \& type II;
$85.2 \%)$, drainage occurred via the coronary sinus, which was significantly lengthened (by about $5 \mathrm{~cm}$ ) and dilated (by about $3 \mathrm{~cm}$ ) when the LSVC drained through it into the right atrium.

\section{Classification of DSVC or LSVC}

Several classification methods have been proposed for the DVSC anomaly. Some authors have suggested that DSVC patients be classified according to the presence or absence of paired azygos veins, and the presence or absence of an anastomotic vein between the RSVC and LSVC (10). Others have suggested that patients be classified based on the presence or absence of an anastomosis and the direction of the inclination (11). Uemura et al. in 2012 proposed a more elaborate classification method of in 24 subtypes under which patients are classified based on the presence and development of both SVCs, the anastomotic ramus, and the azygos veins (12). Conversely, our model took into account the drainage patterns of the LSVC in addition to the presence or absence of both the LBCV and an anastomotic vein. The drainage pattern was added to the classification model because LSVC drainage is closely related to hemodynamic changes. For example, as we reported, the coronary sinus is significantly lengthened and dilated when the LSVC drained via the coronary sinus into the right atrium in type I and type II patients. An enlarged coronary sinus may result from a significant quantity of venous blood returning to it as it collects both cardiac venous blood and LSVC blood. Furthermore, we reported the frequency of observations of the different types using the new classification method. Type I, was found to be the most frequent (51.6\%), followed by type II (33.6\%), type III (11.7\%), and type IV (3.1\%). No comparisons were made with previous reports since they were often case reports with a limited number of DSVC cases. Another 
of our study's strengths is that we not only proposed an easy and practical classification method but also provided quantitative data that is clinically useful, especially in an era of increasing cardiovascular catheterizations and procedures. Yet, our classification method did not embrace all possible variants of an LSVC, such as an LSVC with drainage to the left atrium or other rare conditions (e.g., LSVC present but RSVC absent). When observed, they may be classified as other types.

\section{Imaging modalities in diagnosing DSVC or LSVC}

CT is an effective and accurate imaging modality for assessing DSVC (13). It allows a large field of view and multiplane analysis, and powerful post-processing techniques further improve data utilization efficiency. On cross-sectional image planes, an LSVC manifests as a round nodule situated on the left side of the aortic arch and can be mistaken for lymphadenopathy. Coronally reconstructed images can confirm the presence of the LSVC and show its adjacent structures and anatomical course, as well as the drainage pattern of the LSVC in selected patients (14). Although non-enhanced CT may show the presence of an LSVC, small LSVCs can be missed, particularly when they are draining through an anastomotic vein into the RSVC, as the LSVC in this case is often collapsed. Thus, for patients with an undefined drainage site in non-enhanced CT or for those who need further treatment, contrast-enhanced $\mathrm{CT}$ or angiography is required. But CTA can sometimes miss the drainage patterns of a bilateral SVC and might not clearly display blood flow direction. The scanning interval after a contrast injection can also affect diagnostic accuracy. Other imaging modalities, such as echocardiography and cardiovascular magnetic resonance imaging (CMR), can also be used to evaluate the LSVC (13). Echocardiography is easily available and can be used at the patient's bedside. Yet, it is often limited by acoustic windows and is less accurate than cross-sectional imaging modalities. CMR is an advanced imaging method, which could allow for accurate assessment of cardiovascular morphology, function, and tissue characterization in a single examination. However, CMR is not as widespread as echocardiography and CT due to its high technical demands and cost.

\section{Clinical implications}

The presence of an LSVC has several clinical implications. First, it may complicate the placement of central venous catheters or the implantation of cardiovascular devices because of the technical difficulties involved in passing the catheter through the narrow opening of the coronary sinus into the right heart when using a left superior venous approach. Such cases may lead to injury of the vessel wall, incorrect positioning of the catheter, or more serious complications, such as cardiac arrest $(2,4,15,16)$. The presence of an LSVC may also necessitate the use of a preshaped stylet (pigtail, J-shaped, L-shaped, or U-shaped) or require the formation of a wide loop within the right atrium, depending on the device being implanted (2). Secondly, retrograde cardioplegia through an LSVC and its tributaries may be ineffective as it can lead to inadequate myocardial perfusion (5). The interruption of the LSVC in patients with coronary sinus ostial atresia may lead to severe myocardial ischemia (17). Moreover, a dilated coronary sinus may theoretically be narrowed by suturing, leading to severe complications (5). In our study, the coronary sinus diameter was tripled in more than $80 \%$ of the patients studied. We believe that the quantitative data provided $a$ priori may guide the selection of an appropriate catheter, catheter placement position, or placement pathway. Thirdly, the LSVC, as the embryological precursor to the ligament of Marshall, has been reported to be implicated in the initiation and maintenance of atrial fibrillation (AF). Ablation of its connections with the coronary sinus, pulmonary vein, and left atrium may be used for complete electrical isolation $(8,9,18)$.

\section{Limitations}

This study has some limitations. First, only CT imaging was used for DSVC assessment. Thus, no comparisons were made with other imaging modalities. Secondly, this study focused on the morphological features of DSVC and proposed a novel classification method. Unfortunately, we were unable to address the clinical implications as discussed above since this was not a prospectively designed study, and DSVC was only an incidental finding in most cases. The extent to which quantitative measurements can help to reduce procedure-related risks is still unknown. Further research on how the anomaly affects cardiovascular procedures, its mechanisms in arrhythmogenesis, and strategies to cope with LSVC is warranted.

\section{Conclusions}

DSVC anatomy varies greatly among patients. In 
clinical practice, and especially in an era of increasing cardiovascular procedures, it is desirable that radiologists report on the anatomical subtypes of DSVC, preferably quantitatively. When DSVC is found, clinicians can be alerted of procedure-associated risks and make better clinical decisions. Further large-scale studies are required to explore the clinical implications of DSVC.

\section{Acknowledgments}

Funding: None.

\section{Footnote}

Conflicts of Interest: All authors have completed the ICMJE uniform disclosure form (available at https://dx.doi. org/10.21037/qims-20-1387). The authors have no conflicts of interest to declare.

Ethical Statement: The authors are accountable for all aspects of the work in ensuring that questions related to the accuracy or integrity of any part of the work are appropriately investigated and resolved. The study was conducted in accordance with the Declaration of Helsinki (as revised in 2013). The study was approved by the Ethics Committee of Zhongnan Hospital, Wuhan University and individual consent for this retrospective analysis was waived.

Open Access Statement: This is an Open Access article distributed in accordance with the Creative Commons Attribution-NonCommercial-NoDerivs 4.0 International License (CC BY-NC-ND 4.0), which permits the noncommercial replication and distribution of the article with the strict proviso that no changes or edits are made and the original work is properly cited (including links to both the formal publication through the relevant DOI and the license). See: https://creativecommons.org/licenses/by-nc-nd/4.0/.

\section{References}

1. Edwards J, DuShane J. Thoracic venous anomalies. Arch Pathol 1950:517-37.

2. Ratliff HL, Yousufuddin M, Lieving WR, Watson BE, Malas A, Rosencrance G, McCowan RJ. Persistent left superior vena cava: case reports and clinical implications. Int J Cardiol 2006;113:242-6.

3. Iimura A, Oguchi T, Shibata M, Matsuo M, Takahashi T. Double superior vena cava and anomaly of cardiovascular system with a review of the literature. Okajimas Folia Anat Jpn 2011;88:37-42.

4. Sonavane SK, Milner DM, Singh SP, Abdel Aal AK, Shahir KS, Chaturvedi A. Comprehensive Imaging Review of the Superior Vena Cava. Radiographics 2015;35:1873-92.

5. Hanson EW, Hannan RL, Baum VC. Pulmonary artery catheter in the coronary sinus: implications of a persistent left superior vena cava for retrograde cardioplegia. J Cardiothorac Vasc Anesth 1998;12:448-9.

6. James TN, Marshall TK, Edwards JE. De subitaneis mortibus. XX. Cardiac electrical instability in the presence of a left superior vena cava. Circulation 1976;54:689-97.

7. Morgan DR, Hanratty CG, Dixon LJ, Trimble M, O'Keeffe DB. Anomalies of cardiac venous drainage associated with abnormalities of cardiac conduction system. Europace 2002;4:281-7.

8. Hsu LF, Jaïs P, Keane D, Wharton JM, Deisenhofer I, Hocini M, Shah DC, Sanders P, Scavée C, Weerasooriya R, Clémenty J, Haïssaguerre M. Atrial fibrillation originating from persistent left superior vena cava. Circulation 2004;109:828-32.

9. Maruyama M, Ino T, Miyamoto S, Tadera T, Atarashi H, Kishida H. Characteristics of the electrical activity within the persistent left superior vena cava: comparative view with reference to the ligament of Marshall. J Electrocardiol 2003;36:53-7.

10. Nandy K, Blair CB Jr. Double superior venae cavae with completely paired azygos veins. Anat Rec 1965;151:1-9.

11. Takenoshita H. Persistent left superior vena cava with paired azygos veins--report of a case and an attempt at a new classification. Kaibogaku Zasshi 1986;61:669-82.

12. Uemura M, Suwa F, Takemura A, Toda I, Morishita A. Classification of persistent left superior vena cava considering presence and development of both superior venae cavae, the anastomotic ramus between superior venae cavae, and the azygos venous system. Anat Sci Int 2012;87:212-22.

13. Sheikh AS, Mazhar S. Persistent left superior vena cava with absent right superior vena cava: review of the literature and clinical implications. Echocardiography 2014;31:674-9.

14. Burney K, Young H, Barnard SA, McCoubrie P, Darby M. $\mathrm{CT}$ appearances of congential and acquired abnormalities of the superior vena cava. Clin Radiol 2007;62:837-42.

15. Konstantinou EA, Mariolis Sapsakos TD, Katsoulas TA, Velecheris D, Tsitsimelis D, Bonatsos G. Persistent left superior vena cava leads to catheter malposition during PICC Port placement. J Vasc Access 2016;17:e29-31. 
16. Sahutoglu T, Sakaci T, Kara E, Ahbap E, Basturk T, Koc Y, Sevinc M, Akgol C, Kayarlar AO, Ucar ZA, Caglayan FB, Hasbal NB, Nazif P, Isleem M, Sahutoglu E, Unsal A. Persistent left superior vena cava: Two case reports and a review from nephrologists' perspective. Hemodial Int 2016;20:369-77.

Cite this article as: Zhang L, Ling G, Gang Y, Yang Z, Lu Z, Gan X, Liang H, Zeng Y, Zhang X. Classification and quantification of double superior vena cava evaluated by computed tomography imaging. Quant Imaging Med Surg 2022;12(2):1405-1414. doi: 10.21037/qims-20-1387
17. Muster AJ, Naheed ZJ, Backer CL, Mavroudis C. Is surgical ligation of an accessory left superior vena cava always safe? Pediatr Cardiol 1998;19:352-4.

18. Liu H, Lim KT, Murray C, Weerasooriya R. Electrogramguided isolation of the left superior vena cava for treatment of atrial fibrillation. Europace 2007;9:775-80. 


\section{Supplementary}

Table S1 Subgroup analysis of bilateral SVC and quantitative coronary sinus measurements according to gender, age and BMI: type I (N=66)

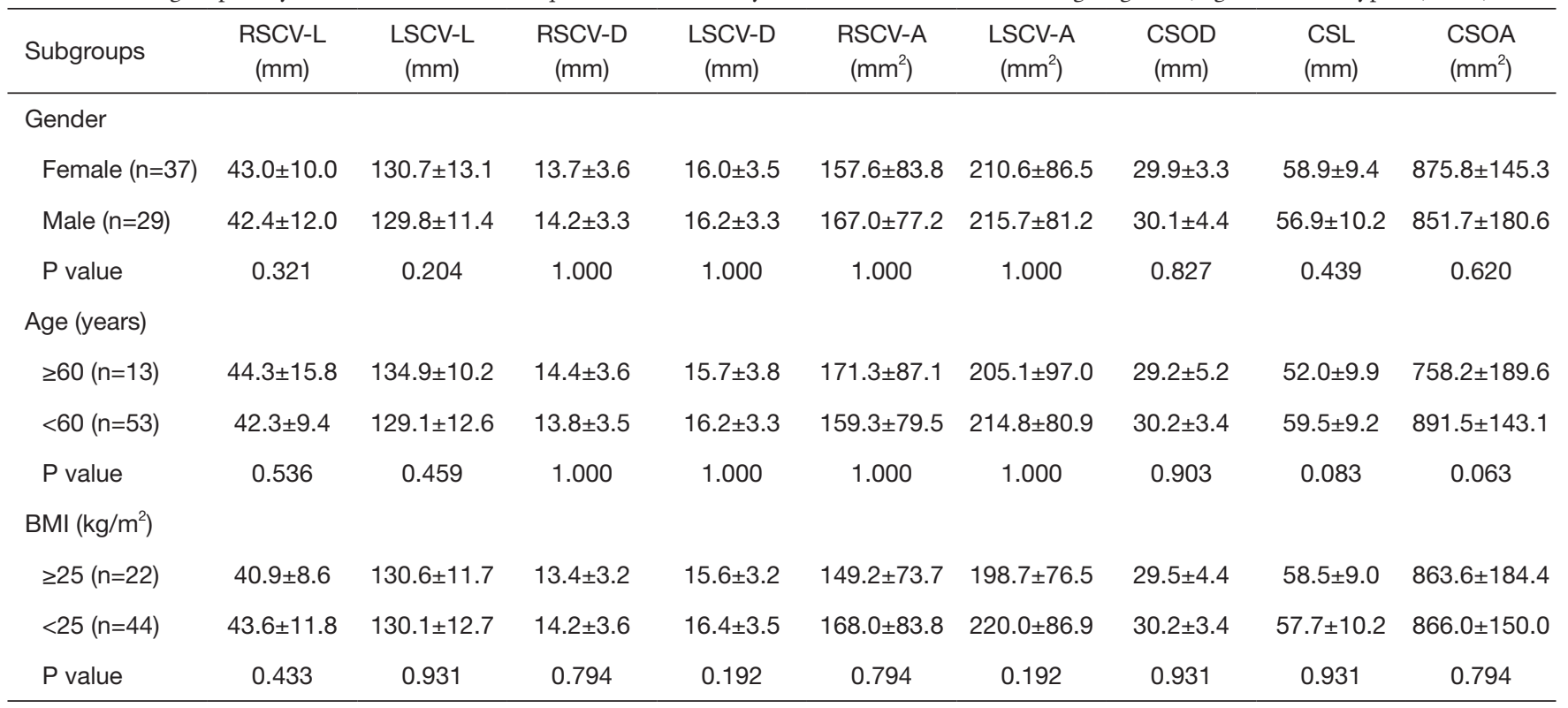

DSVC, double superior vena cava; RSVC-L/LSVC-L, right/left superior vena cava length; RSCV-D/LSCV-D, right/left superior vena cava diameter; RSVC, right superior vena cava; LSVC, left superior vena cava; CSOD, diameter of coronary sinus ostium; CSL, length of coronary sinus; CSOA, area of coronary sinus ostium.

Table S2 Subgroup analysis of bilateral SVC and quantitative coronary sinus measurements according to gender, age, and BMI: type II (N=43)

\begin{tabular}{|c|c|c|c|c|c|c|c|c|c|}
\hline Subgroups & $\begin{array}{c}\text { RSCV-L } \\
(\mathrm{mm})\end{array}$ & $\begin{array}{c}\text { LSCV-L } \\
(\mathrm{mm})\end{array}$ & $\begin{array}{c}\text { RSCV-D } \\
(\mathrm{mm})\end{array}$ & $\begin{array}{l}\text { LSCV-D } \\
\text { (mm) }\end{array}$ & $\begin{array}{c}\text { RSCV-A } \\
\left(\mathrm{mm}^{2}\right)\end{array}$ & $\begin{array}{c}\text { LSCV-A } \\
\left(\mathrm{mm}^{2}\right)\end{array}$ & $\begin{array}{l}\text { CSOD } \\
(\mathrm{mm})\end{array}$ & $\begin{array}{l}\text { CSL } \\
(\mathrm{mm})\end{array}$ & $\begin{array}{l}\text { CSOA } \\
\left(\mathrm{mm}^{2}\right)\end{array}$ \\
\hline \multicolumn{10}{|l|}{ Gender } \\
\hline Female $(n=19)$ & $38.5 \pm 6.8$ & $130.9 \pm 12.7$ & $15.4 \pm 3.3$ & $14.6 \pm 3.8$ & $195.4 \pm 81.5$ & $179.1 \pm 90.4$ & $29.1 \pm 3.7$ & $54.0 \pm 7.7$ & $779.2 \pm 97.7$ \\
\hline Male $(n=24)$ & $47.5 \pm 10.4$ & $129.5 \pm 12.4$ & $15.4 \pm 3.9$ & $14.6 \pm 3.4$ & $196.8 \pm 91.4$ & $176.8 \pm 78.7$ & $27.0 \pm 3.5$ & $53.9 \pm 10.4$ & $724.4 \pm 154.4$ \\
\hline$\geq 60(n=10)$ & $38.9 \pm 7.4$ & $127.6 \pm 11.6$ & $15.4 \pm 3.5$ & $13.2 \pm 3.3$ & $194.5 \pm 82.0$ & $143.6 \pm 71.2$ & $27.8 \pm 2.5$ & $52.2 \pm 9.4$ & $724.8 \pm 148.2$ \\
\hline$<60(n=33)$ & $44.9 \pm 10.3$ & $130.9 \pm 12.8$ & $15.4 \pm 3.7$ & $15.1 \pm 3.6$ & $196.7 \pm 88.6$ & $188.2 \pm 84.5$ & $28.0 \pm 4.0$ & $54.5 \pm 9.2$ & $755.8 \pm 130.8$ \\
\hline$P$ value & 0.782 & 0.782 & 0.782 & 0.318 & 0.782 & 0.318 & 0.539 & 0.405 & 0.782 \\
\hline$P$ value & 0.287 & 0.843 & 0.843 & 0.843 & 0.843 & 0.843 & 0.971 & 0.971 & 0.843 \\
\hline
\end{tabular}

DSVC, double superior vena cava; RSVC-L/LSVC-L, right/left superior vena cava length; RSCV-D/LSCV-D, right/left superior vena cava diameter; RSVC, right superior vena cava; LSVC, left superior vena cava; CSOD, diameter of coronary sinus ostium; CSL, length of coronary sinus; CSOA, area of coronary sinus ostium. 
Table S3 Subgroup analysis of bilateral SVC and quantitative coronary sinus measurements according to gender, age, and BMI: type III (N=15)

\begin{tabular}{|c|c|c|c|c|c|c|c|c|c|}
\hline Subgroups & $\begin{array}{c}\text { RSCV-L } \\
(\mathrm{mm})\end{array}$ & $\begin{array}{c}\text { LSCV-L } \\
(\mathrm{mm})\end{array}$ & $\begin{array}{l}\text { RSCV-D } \\
(\mathrm{mm})\end{array}$ & $\begin{array}{l}\text { LSCV-D } \\
(\mathrm{mm})\end{array}$ & $\begin{array}{c}\text { RSCV-A } \\
\left(\mathrm{mm}^{2}\right)\end{array}$ & $\begin{array}{c}\text { LSCV-A } \\
\left(\mathrm{mm}^{2}\right)\end{array}$ & $\begin{array}{l}\text { CSOD } \\
(\mathrm{mm})\end{array}$ & $\begin{array}{c}\mathrm{CSL} \\
(\mathrm{mm})\end{array}$ & $\begin{array}{l}\text { CSOA } \\
\left(\mathrm{mm}^{2}\right)\end{array}$ \\
\hline \multicolumn{10}{|l|}{ Gender } \\
\hline Male $(n=9)$ & $45.9 \pm 12.7$ & $103.2 \pm 12.2$ & $14.6 \pm 3.7$ & $16.7 \pm 3.8$ & $177.7 \pm 81.8$ & $229.5 \pm 95.7$ & $10.9 \pm 1.9$ & $32.9 \pm 10.4$ & $175.8 \pm 61.1$ \\
\hline$\geq 60(n=6)$ & $48.3 \pm 9.6$ & $101.3 \pm 15.3$ & $15.3 \pm 5.2$ & $17.6 \pm 3.8$ & $197.1 \pm 112.3$ & $251.9 \pm 99.7$ & $10.7 \pm 0.8$ & $34.0 \pm 8.0$ & $180.1 \pm 30.1$ \\
\hline$<60(\mathrm{n}=9)$ & $42.3 \pm 10.7$ & $100.7 \pm 9.4$ & $13.6 \pm 3.2$ & $15.8 \pm 3.4$ & $152.2 \pm 71.7$ & $203.4 \pm 86.2$ & $11.3 \pm 2.0$ & $34.3 \pm 10.0$ & $193.7 \pm 76.0$ \\
\hline$P$ value & 0.569 & 10.000 & 0.569 & 0.569 & 0.569 & 0.569 & 0.200 & 1.000 & 0.569 \\
\hline$P$ value & 1.000 & 1.000 & 0.282 & 0.282 & 0.282 & 0.282 & 0.569 & 0.282 & 1.000 \\
\hline
\end{tabular}

DSVC, double superior vena cava; RSVC-L/LSVC-L, right/left superior vena cava length; RSCV-D/LSCV-D, right/left superior vena cava diameter; RSVC, right superior vena cava; LSVC, left superior vena cava; CSOD, diameter of coronary sinus ostium; CSL, length of coronary sinus; CSOA, area of coronary sinus ostium.

Table S4 Subgroup analysis of bilateral SVC and quantitative coronary sinus measurements according to gender, age, and BMI: type IV (N=4)

\begin{tabular}{|c|c|c|c|c|c|c|c|c|c|}
\hline Subgroups & $\begin{array}{c}\text { RSCV-L } \\
(\mathrm{mm})\end{array}$ & $\begin{array}{c}\text { LSCV-L } \\
(\mathrm{mm})\end{array}$ & $\begin{array}{l}\text { RSCV-D } \\
(\mathrm{mm})\end{array}$ & $\begin{array}{l}\text { LSCV-D } \\
(\mathrm{mm})\end{array}$ & $\begin{array}{c}\text { RSCV-A } \\
\left(\mathrm{mm}^{2}\right)\end{array}$ & $\begin{array}{c}\text { LSCV-A } \\
\left(\mathrm{mm}^{2}\right)\end{array}$ & $\begin{array}{l}\text { CSOD } \\
(\mathrm{mm})\end{array}$ & $\begin{array}{c}\mathrm{CSL} \\
(\mathrm{mm})\end{array}$ & $\begin{array}{l}\text { CSOA } \\
\left(\mathrm{mm}^{2}\right)\end{array}$ \\
\hline \multicolumn{10}{|l|}{ Gender } \\
\hline Male $(n=3)$ & $45.2 \pm 11.1$ & $102.0 \pm 12.5$ & $14.3 \pm 3.3$ & $13.4 \pm 3.1$ & $167.0 \pm 69.9$ & $146.1 \pm 64.8$ & $11.6 \pm 2.5$ & $36.0 \pm 13.2$ & $214.6 \pm 116.8$ \\
\hline$\geq 60(n=1)$ & 56.8 & 116.0 & 10.6 & 10.2 & 88.2 & 81.7 & 9.0 & 34.9 & 156.4 \\
\hline$<60(\mathrm{n}=3)$ & $39.6 \pm 4.8$ & $95.7 \pm 3.2$ & $17.1 \pm 1.6$ & $16.2 \pm 2.5$ & $230.1 \pm 43.8$ & $209.4 \pm 63.2$ & $12.2 \pm 1.6$ & $34.0 \pm 13.9$ & $214.6 \pm 116.8$ \\
\hline$P$ value & 1.000 & 1.000 & 1.000 & 1.000 & 1.000 & 1.000 & 1.000 & 1.000 & 1.000 \\
\hline$P$ value & 1.000 & 1.000 & 1.000 & 1.000 & 1.000 & 1.000 & 1.000 & 1.000 & 1.000 \\
\hline
\end{tabular}

DSVC, double superior vena cava; RSVC-L/LSVC-L, right/left superior vena cava length; RSCV-D/LSCV-D, right/left superior vena cava diameter; RSVC, right superior vena cava; LSVC, left superior vena cava; CSOD, diameter of coronary sinus ostium; CSL, length of coronary sinus; CSOA, area of coronary sinus ostium. 